\title{
Protein Stabilized Liposomal Docetaxel Nanoparticles
}

National Cancer Institute

\section{Source}

National Cancer Institute. Protein Stabilized Liposomal Docetaxel Nanoparticles. NCI

Thesaurus. Code C90534.

A formulation containing protein-stabilized liposome nanoparticles encapsulating the poorly water-soluble, second-generation taxane analog docetaxel with antineoplastic activity. Docetaxel binds to and stabilizes the beta-tubulin subunit, thereby inhibiting microtubule disassembly which results in cell-cycle arrest at the G2/M phase and cell death. This agent also inhibits pro-angiogenic factors such as vascular endothelial growth factor (VEGF) and displays immunomodulatory and pro-inflammatory properties by inducing various mediators of the inflammatory response. Compared to the use of toxic carriers to increase solubilization of docetaxel, protein-stabilized liposomal docetaxel improves drug solubility while avoiding carrier-associated toxicity. 